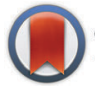

CrossMark \& click for updates

Cite this: Soft Matter, 2016, 12,3730

Received 6th October 2015, Accepted 3rd March 2016

DOI: $10.1039 / \mathrm{c} 5 \mathrm{sm} 02489 \mathrm{~g}$

www.rsc.org/softmatter

\section{Columnar propeller-like 1,3,5-triphenylbenzenes: the missing link of shape-persistent hekates $\dagger$}

\author{
Tobias Wöhrle, ${ }^{a}$ Stuart James Beardsworth, ${ }^{a}$ Christopher Schilling, ${ }^{a}$ Angelika Baro, ${ }^{a}$ \\ Frank Giesselmann ${ }^{\mathrm{b}}$ and Sabine Laschat ${ }^{* a}$
}

\begin{abstract}
Triphenylbenzenes with different substitution patterns at the outer phenyl rings have been successfully synthesised. Sixfold $n$-alkoxy substitution was insufficient for mesomorphism, but already increasing the number of side chains by three methoxy groups led to liquid crystalline behaviour and mesophase formation. Symmetrical triphenylbenzenes with nine $n$-alkoxy side chains ( $\geq$ C9) formed broad enantiotropic mesophases. The symmetry of the liquid crystalline phases was unambiguously determined by $\mathrm{X}$-ray diffraction measurements as Coln and Colno for symmetry-reduced methoxy-alkoxy derivatives and symmetrical nona-alkoxy-triphenylbenzenes, respectively. Based on X-ray diffraction data a stacking model was proposed in which the single molecules aggregate to helical columns forming a mesophase.
\end{abstract}

\section{Introduction}

Discotic liquid crystals, which self-assemble into columnar mesophases, have been intensively studied over the last few decades, because their anisotropic properties, high 1D charge carrier mobility and self-healing of defects make them attractive for molecular electronics. ${ }^{1,2}$ Star-shaped mesogens with three or more arms pointing to the vortices of $2 \mathrm{D}$ polygons or 3D polyhedra are among the various discotic liquid crystals. The star topology provides access to oligomers and dendrimers with a well-defined size and allows further functionalization of the arms. ${ }^{3}$ A particularly interesting subfamily are the shapepersistent hekates, i.e. star-shaped mesogens with three arms such as phenyl, oligophenylene, oligo(het)arylene, or oligo(phenylenevinylene) groups, because the space between the arms cannot be compensated by folding. Thus, simple columnar stacking of the central aromatic cores does not provide sufficient nanosegregation required for the formation of stable columnar mesophases. In such systems space filling and nanosegregation are often achieved by rotating neighboring molecules by a certain angle along the intracolumnar axis. This self-assembly can be further enforced by hydrogen bonding. In some cases helical columnar stacking is possible, even in the absence of chiral substituents. ${ }^{4-11}$ Therefore, these compounds allow a detailed view into the interplay between the molecular structure

\footnotetext{
${ }^{a}$ Institut für Organische Chemie, Universität Stuttgart, Pfaffenwaldring 55, D-70569 Stuttgart, Germany.E-mail: sabine.laschat@oc.uni-stuttgart.de

${ }^{b}$ Institut für Physikalische Chemie, Universität Stuttgart, Pfaffenwaldring 55, D-70569 Stuttgart, Germany

$\dagger$ Electronic supplementary information (ESI) available. See DOI: 10.1039/ c5sm02489g
}

and modes of the self-assembly. While star-shaped tris-styrylbenzene $1^{12-20}$ and the corresponding tris-styryltriazine $2^{21-23}$ as well as 1,3,5-triphenyltriazine 3 have been extensively studied, ${ }^{24-34}$ the parent 1,3,5-triphenylbenzenes 5 and 7 are much less explored $^{24,35-37}$ (Scheme 1).

In particular, Scherowsky ${ }^{38}$ and Kotha ${ }^{24}$ reported that bisalkoxy-substituted 1,3,5-triphenylbenzenes do not show
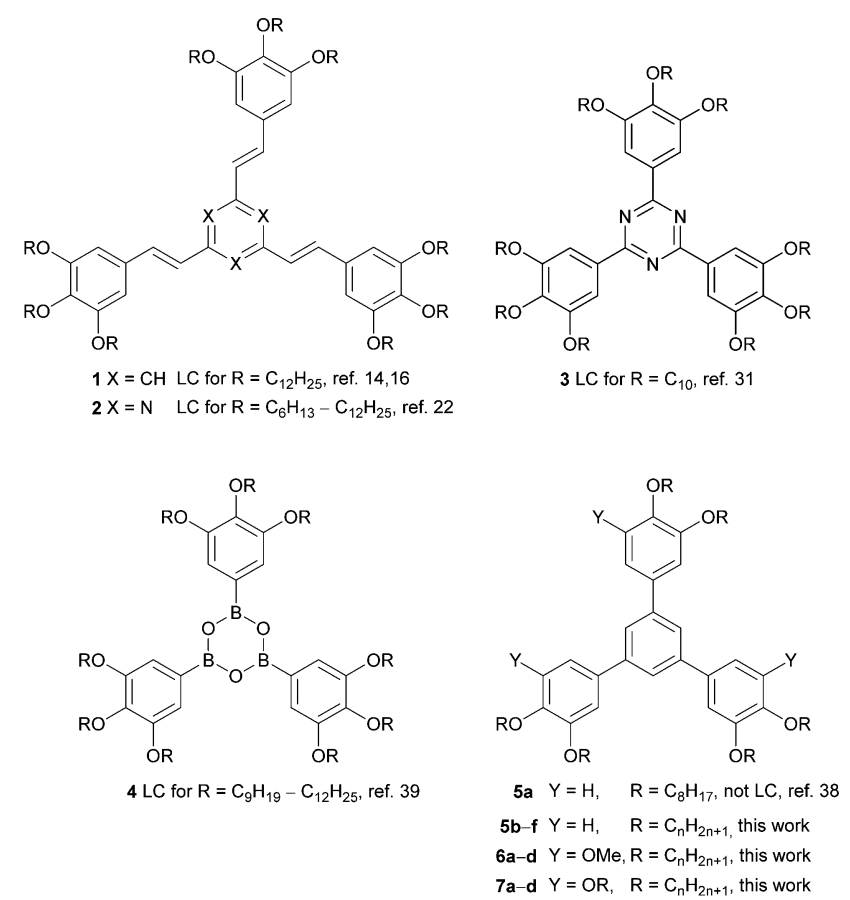

Scheme 1 Known shape-persistent hekates $\mathbf{1 - 5 a}$ and related novel compounds $\mathbf{5 b - f}, \mathbf{6}$ and $\mathbf{7}$. 
any mesomorphic properties. Only for the corresponding donor-acceptor complexes with trinitrofluorenone (TNF) and C8 chains in the triphenylbenzene columnar mesophases were observed. In light of these results ${ }^{24,38}$ triphenylbenzenes 5 with only six short alkoxy substituents $(<\mathrm{C} 9)$ were deemed unsuitable as mesogens and thus only hexa- and nona-substituted derivatives bearing longer side chains (C9-C18) were considered further. We were curious whether the missing link in star shaped discotics, i.e. the simple bis- or trisalkoxy-substituted triphenylbenzenes with columnar mesomorphism in the neat form, could be obtained. In addition, due to the fact that the corresponding planar tris(trialkoxyphenyl)triazine $3^{31}$ and tris(trialkoxyphenyl)boroxine $4^{39}$ display stable columnar mesophases over a broad temperature range, it was of interest how the propeller-shape of triphenylbenzenes 5-7 affects the selfassembly behaviour in comparison with 3 and $\mathbf{4}$. The results are reported below.

\section{Synthesis of triphenylbenzenes}

Hexaalkoxy-1,3,5-triphenylbenzenes 5 were prepared by Suzuki cross-coupling of borolanes $\mathbf{8}^{40}$ with 1,3,5-tribromobenzene in moderate to good yields (33-75\%) (Scheme 2). Derivative $\mathbf{5 f}$

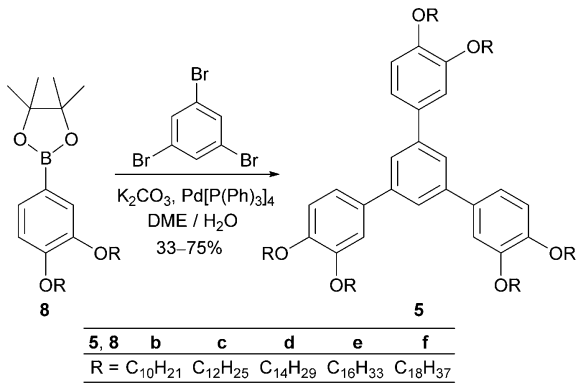

Scheme 2 Preparation of non-symmetrical triphenylbenzene $\mathbf{5}$. with C18 alkoxy side chains, however, was obtained in only $7 \%$ due to solubility problems during purification.

Triphenylbenzenes 6 with decreased symmetry in the substitution pattern of the aryl ring were synthesized from commercially available 1,2,3-trimethoxy-5-bromobenzene 9 (Scheme 3). Selective demethylation of $\mathbf{9},{ }^{41}$ Williamson etherification and borylation gave methoxy-bisalkoxy-substituted borolanes 11, which were submitted to Suzuki cross-coupling providing the desired triphenylbenzenes 6 in 10-25\% total yield.

The symmetrically nona-alkoxy-substituted triphenylbenzenes 7 were accessible in $16-17 \%$ total yield from 9 via borolane $12^{40}$ followed by Suzuki cross-coupling, demethylation and finally Williamson etherification (Scheme 3). This route is advantageous due to the less amount of expensive reagent $\mathrm{BBr}_{3}$ for the demethylation of $\mathbf{1 3}$ to $\mathbf{1 4}^{38}$ and fewer purification steps.

\section{DSC and POM investigations}

The liquid crystalline properties of compounds 5-7 were first studied by differential scanning calorimetry (DSC). As the known sixfold octyloxy-substituted triphenylbenzene $\mathbf{5 a},{ }^{38}$ the higher homologues $\mathbf{5 b - f}$ did not show any mesomorphic behaviour. In contrast, both the non-symmetrical derivatives 6 and symmetrical compounds 7 with nine peripheral alkoxy side chains form stable enantiotropic mesophases. The results of the DSC investigations are summarised in Table 1 (for original DSC traces see ESI $\dagger$ ).

In contrast to the sixfold substituted derivatives $\mathbf{5}$ tris(dialkoxy-methoxyphenyl)benzenes $\mathbf{6}$ displayed different phase behaviour depending on their chain lengths. For $\mathbf{6 a , b}$ with shorter alkyl chains (C9 and C10) no melting points were visible, neither in the heating nor in the cooling scans. Both derivatives showed distinctive glass transitions at $53{ }^{\circ} \mathrm{C}$ and $51{ }^{\circ} \mathrm{C}$, respectively, in the second heating cycle. Upon further heating clearing from the mesophase to the isotropic liquid

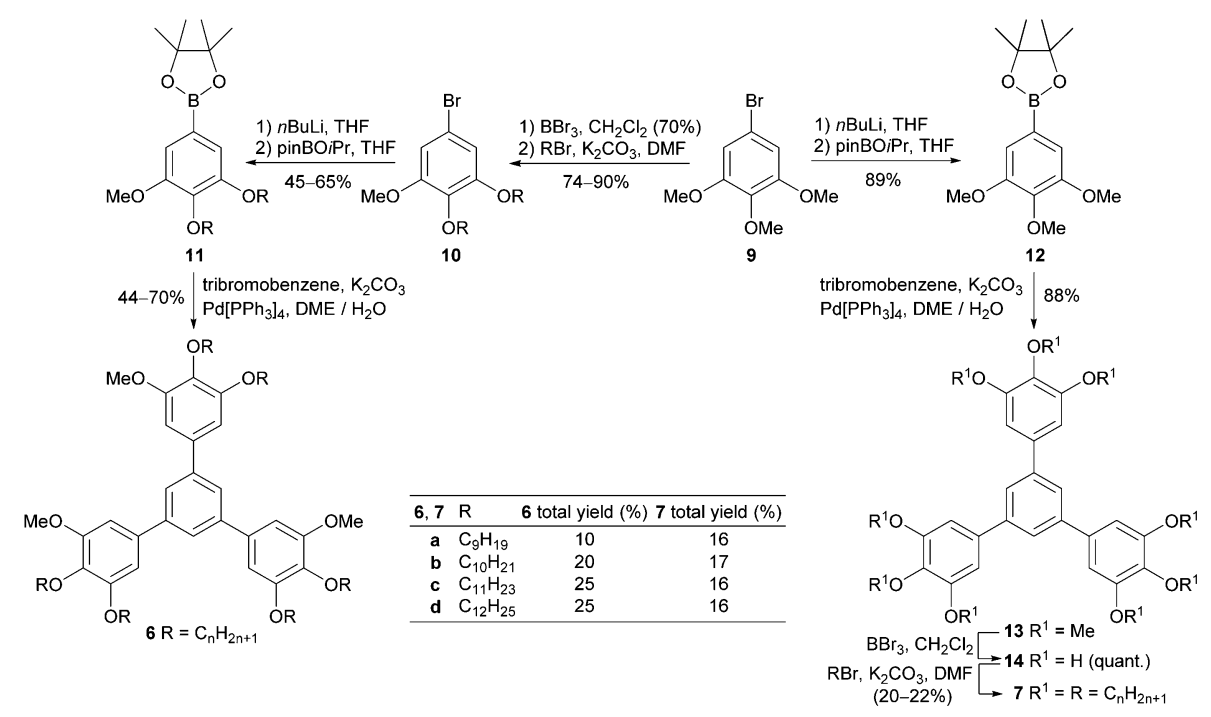

Scheme 3 Preparation of triphenylbenzene derivatives $\mathbf{6}$ and $\mathbf{7}$. 
Table 1 Thermotropic data of the mesogenic triphenylbenzenes $\mathbf{6}$ and $\mathbf{7}$ obtained by DSC (heating/cooling rate $5 \mathrm{~K} \mathrm{~min}^{-1}$, onset values) ${ }^{a}$

$T_{\mathrm{m}}\left({ }^{\circ} \mathrm{C}\right)$

$T_{\mathrm{c}}\left({ }^{\circ} \mathrm{C}\right)$

Compd Phase $\left(\Delta H / \mathrm{kJ} \mathrm{mol}^{-1}\right)$ Phase $\left(\Delta H / \mathrm{kJ} \mathrm{mol}^{-1}\right)$ Phase Cycles

\begin{tabular}{|c|c|c|c|c|c|c|}
\hline \multirow[t]{2}{*}{$6 a$} & G & $53\left(T_{\mathrm{g}}\right)$ & $\mathrm{Col}_{\mathrm{ho}}$ & $126(30.0)$ & I & 2nd heating \\
\hline & G & $90\left(T_{\mathrm{g}}\right)$ & $\mathrm{Col}_{\mathrm{ho}}$ & $123(30.4)$ & I & 2nd cooling \\
\hline \multirow[t]{2}{*}{$6 b$} & G & $51\left(T_{\mathrm{g}}\right)$ & $\mathrm{Col}_{\mathrm{ho}}$ & $121(35.4)$ & I & 2nd heating \\
\hline & G & $86\left(T_{\mathrm{g}}\right)$ & $\mathrm{Col}_{\mathrm{ho}}$ & $119(34.3)$ & I & 2nd cooling \\
\hline \multirow[t]{2}{*}{$6 c$} & $\mathrm{Cr}$ & $35(33.2)$ & $\mathrm{Col}_{\mathrm{h}}$ & $113(27.7)$ & I & 2nd heating \\
\hline & $\mathrm{Cr}$ & $5(20.1)$ & $\mathrm{Col}_{\mathrm{h}}$ & $113(30.5)$ & I & 2nd cooling \\
\hline \multirow[t]{2}{*}{ 6d } & $\mathrm{Cr}$ & $52(55.1)$ & $\mathrm{Col}_{\mathrm{h}}$ & $110(25.3)$ & I & 2nd heating \\
\hline & $\mathrm{Cr}$ & $23(41.7)$ & $\mathrm{Col}_{\mathrm{h}}$ & $110(24.5)$ & I & 2nd cooling \\
\hline \multirow[t]{2}{*}{$7 a$} & $\mathrm{Cr}$ & $29(41.3)$ & $\mathrm{Col}_{\mathrm{ho}}$ & $143(63.3)$ & I & 2nd heating \\
\hline & $\mathrm{Cr}$ & $28(42.5)$ & $\mathrm{Col}_{\mathrm{ho}}$ & $139(68.8)$ & I & 2nd cooling \\
\hline \multirow[t]{2}{*}{$7 \mathbf{b}$} & $\mathrm{Cr}$ & 41 (40.9) & $\mathrm{Col}_{\mathrm{ho}}$ & $140(67.0)$ & I & 2nd heating \\
\hline & $\mathrm{Cr}$ & $38(40.8)$ & $\mathrm{Col}_{\mathrm{ho}}$ & 135 (69.7) & I & 2nd cooling \\
\hline \multirow[t]{2}{*}{$7 c$} & $\mathrm{Cr}$ & $49(74.1)$ & $\mathrm{Col}_{\text {ho }}$ & $136(66.9)$ & I & 2nd heating \\
\hline & $\mathrm{Cr}$ & $47(52.3)$ & $\mathrm{Col}_{\mathrm{ho}}$ & $131(67.1)$ & I & 2nd cooling \\
\hline \multirow[t]{2}{*}{$7 d$} & $\mathrm{Cr}$ & $59(98.3)$ & $\mathrm{Col}_{\text {ho }}$ & $130(63.1)$ & I & 2nd heating \\
\hline & $\mathrm{Cr}$ & $52(82.0)$ & $\mathrm{Col}_{\mathrm{ho}}$ & $127(58.9)$ & I & 2nd cooling \\
\hline
\end{tabular}

${ }^{a}$ Melting point $\left(T_{\mathrm{m}}\right)$, clearing point $\left(T_{\mathrm{c}}\right)$, glass transition temperature $\left(T_{\mathrm{g}}\right)$, crystalline phase $(\mathrm{Cr})$, and glassy state $(\mathrm{G})$. $\mathrm{Col}_{\mathrm{h}}$ : columnar hexagonal phase, $\mathrm{Col}_{\text {ho: }}$ ordered columnar hexagonal phase, and I: isotropic liquid.

took place at $126{ }^{\circ} \mathrm{C}$ for $6 \mathbf{a}$ and $121{ }^{\circ} \mathrm{C}$ for $\mathbf{6 b}$. In the cooling cycle formation of the mesophase took place at $123{ }^{\circ} \mathrm{C}$ and $119^{\circ} \mathrm{C}$, respectively. The glass transitions were shifted to higher temperatures $\left(90{ }^{\circ} \mathbf{C}\right.$ for $6 \mathbf{a}$ and $86{ }^{\circ} \mathbf{C}$ for $\left.6 \mathbf{b}\right)$ reducing the mesophase width by half to $33 \mathrm{~K}$ for both compounds.

Triphenylbenzenes $\mathbf{6 c}$ and $\mathbf{6 d}$ with longer alkoxy side chains (C11 and C12) displayed reproducible melting, at $35{ }^{\circ} \mathrm{C}$ and $52{ }^{\circ} \mathrm{C}$, and clearing peaks at $113{ }^{\circ} \mathrm{C}$ and $110{ }^{\circ} \mathrm{C}$, respectively, upon heating. Whilst the temperatures of the clearing points are maintained in the cooling cycle with respect to those measured upon heating supercooling was observed for the mesophase-to-crystalline transitions. Crystallisation took place at $5{ }^{\circ} \mathrm{C}$ and $23{ }^{\circ} \mathrm{C}$, respectively, giving mesophase widths of $108 \mathrm{~K}$ for $\mathbf{6 c}$ and $87 \mathrm{~K}$ for $\mathbf{6 d}$.

All tris(trialkoxyphenyl)benzenes 7a-d formed stable mesophases, displaying increasing melting points from $29^{\circ} \mathrm{C}(7 \mathbf{a})$ to $59{ }^{\circ} \mathrm{C}$ (7d) with increasing chain lengths. Conversely, the clearing points decreased with increasing chain length from $143{ }^{\circ} \mathrm{C}$ (7a) to $130{ }^{\circ} \mathrm{C}(\mathbf{7 d})$ whereby the mesophase widths decrease linearly through the series with increasing alkoxy chain length. This behaviour is in good agreement with the structurally related triphenylboroxine $4 .^{39}$

Under a polarizing optical microscope (POM) all compounds gave textures typical of those for columnar mesophases (Fig. 1). $\mathbf{6 a}$ and $7 \mathbf{a}$ displayed broken fan textures, $\mathbf{6 c}$ displayed a pseudofocal conic texture, and $\mathbf{6 b}, \mathbf{6} \mathbf{d}$ and $\mathbf{7 b}-\mathbf{d}$ displayed fan-shaped textures. ${ }^{42}$ All textures also exhibited small homeotropic areas which are common for uniaxial columnar mesophases.

\section{X-ray diffraction (XRD) investigations}

Further insight into the mesophase geometries of $\mathbf{6 a - d}$ and $7 \mathbf{a}-\mathbf{d}$ came from X-ray diffraction measurements. Two derivatives of
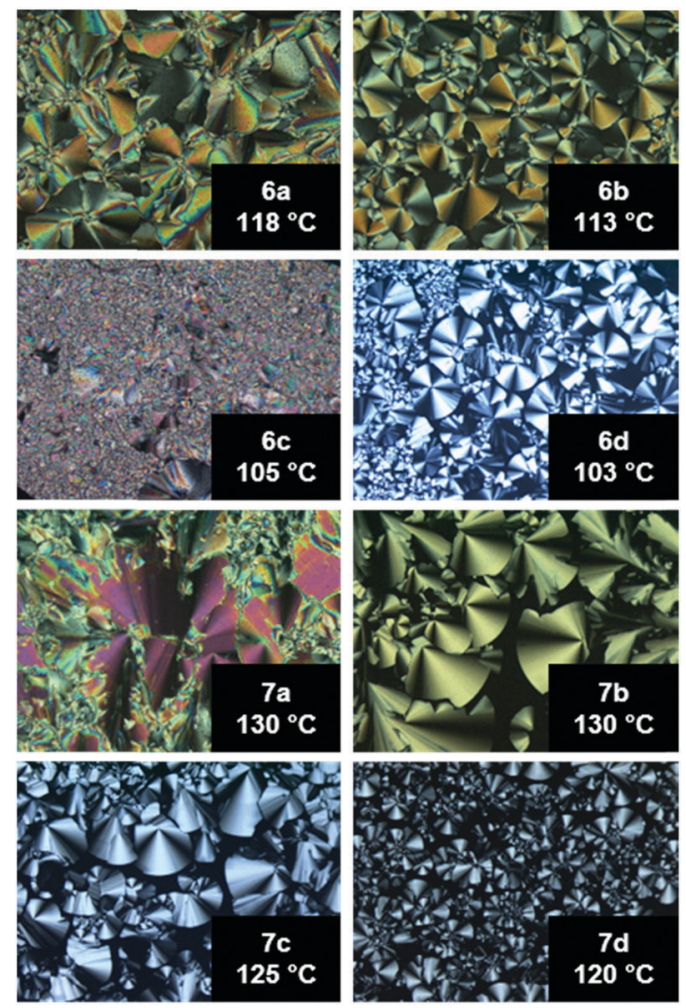

Fig. 1 POM images of $\mathbf{6 a - d}$ and $7 \mathbf{a}-\mathbf{d}$ upon cooling from the isotropic liquid (cooling rate $1 \mathrm{~K} \mathrm{~min}^{-1}$ and magnification $\times 100$ ).

each type of mesogen with different substitution patterns, namely $\mathbf{6 a}, \mathbf{6 d}, \mathbf{7 b}$ and $\mathbf{7 d}$, were representatively investigated (SAXS and WAXS, for further details see Table S2, ESI $\dagger$ ). The SAXS profile and the corresponding diffraction pattern of $\mathbf{6 a}$ showed two reflexes which were assigned as (10) and (20) as they are in a relative ratio of $1: 1 / 2$ (Fig. 3a). ${ }^{43}$ This set of signals might be assigned to a discotic lamellar phase geometry ${ }^{44}$ due to the missing (11) peak which would be necessary for an unambiguous assignment of $\mathrm{Col}_{\mathrm{h}}$ phase geometry. However, the partially oriented SAXS pattern (Fig. 2a, inset) clearly indicates a hexagonal lattice. In the SAXS diffractogram of $\mathbf{6 d}$ four reflexes in a ratio of $1: 1 / \sqrt{ } 3: 1 / \sqrt{ } 7: 1 / \sqrt{ } 9$ were visible (Fig. 2b), which have been unambiguously assigned as (10), (11), (21) and (30). Despite the missing (20) peak, which might occur due to superimposing of areas with different orientation in the sample, the observed reflexes were in good agreement with $\mathrm{a} \mathrm{Col}_{\mathrm{h}}$ lattice.

The small-angle X-ray scattering profile and the diffraction pattern of $\mathbf{7 b}$ are depicted in Fig. 3a. The SAXS pattern (Fig. 3a inset) is highly ordered and exhibits an oriented hexagon of the innermost reflection together with four additional sets of oriented reflections. Integration of the inner hexagon over $2 \Theta$ is shown in Fig. 3b. The relative angle of $60( \pm 2)^{\circ}$ between the peaks indicates a hexagonal columnar mesophase. In the smallangle region five reflections were visible in a ratio of $1: 1 / \sqrt{ } 3: 1 /$ $2: 1 / \sqrt{ } 7: 1 / \sqrt{ } 9$ which were indicated as (10), (11), (20), (21) and (30), confirming a hexagonal lattice (Fig. 3a). ${ }^{43}$

The SAXS investigations of $\mathbf{7 d}$ (Fig. 3c) confirmed the results of the previous XRD experiments. The SAXS profile displayed 
a)

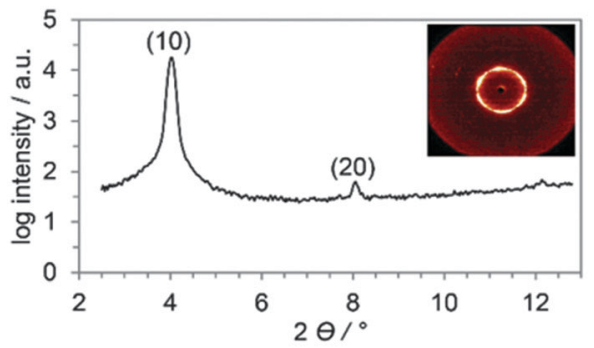

b)

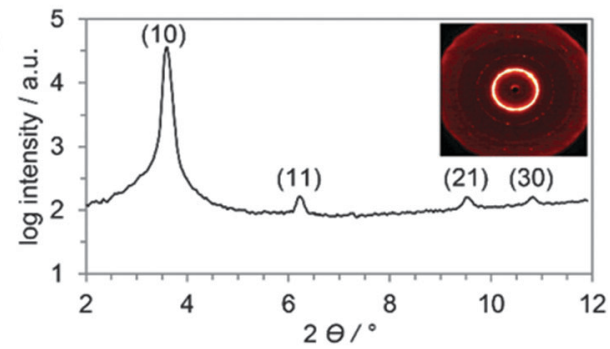

Fig. 2 SAXS profile and diffraction pattern (inset) during cooling of (a) $\mathbf{6 a}$ at $105^{\circ} \mathrm{C}$ and (b) $6 \mathbf{d} 85^{\circ} \mathrm{C}$.

five reflections in the ratio of $1: 1 / \sqrt{ } 3: 1 / 2: 1 / \sqrt{ } 7: 1 / \sqrt{ } 12$ which fit to a hexagonal lattice and were therefore indicated as (10), (11), (21), (30), and (22) (Fig. 3c).

a)

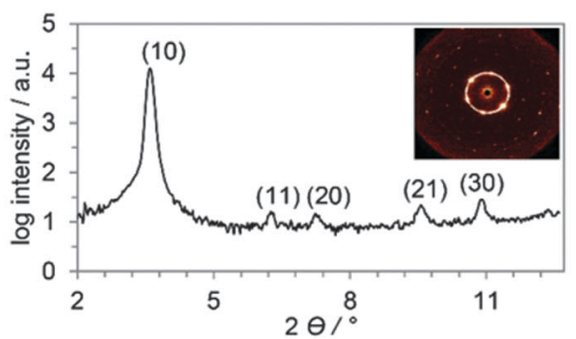

b)

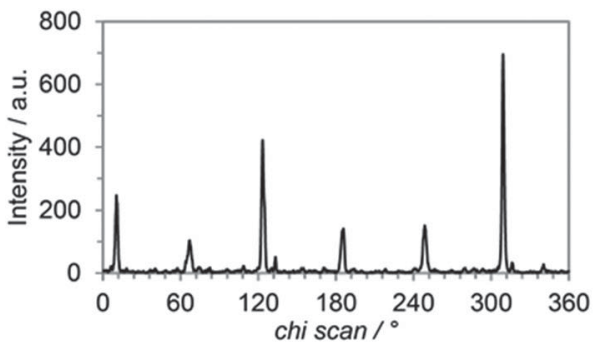

c)

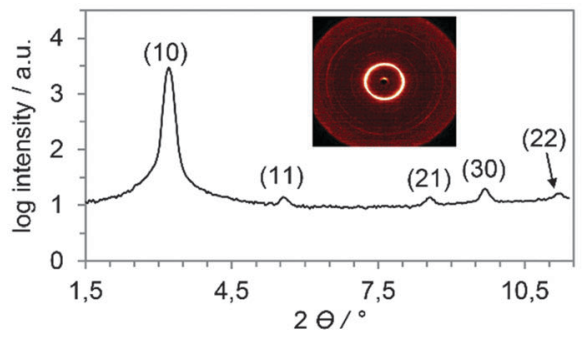

Fig. 3 (a) SAXS profile and diffraction pattern (inset) of $7 \mathbf{b}$ during cooling at $88{ }^{\circ} \mathrm{C}$, (b) azimuthal intensity profile of the innermost hexagon in the SAXS pattern, and (c) SAXS profile and diffraction pattern (inset) of $\mathbf{7 d}$ during cooling at $90^{\circ} \mathrm{C}$. a)

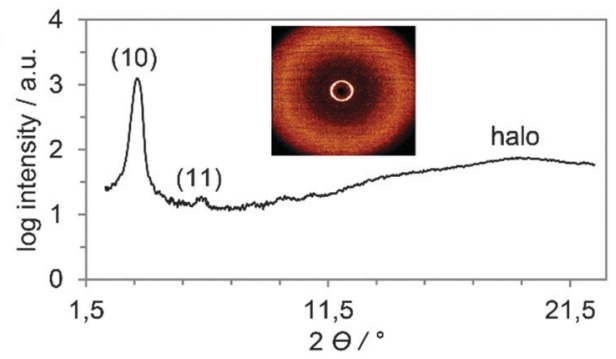

b)

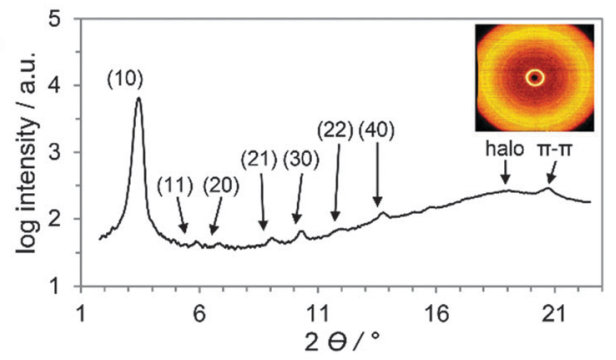

Fig. 4 (a) WAXS profile and diffraction pattern (inset) of $\mathbf{6 d}$ during cooling at $85{ }^{\circ} \mathrm{C}$ and (b) WAXS profile and diffraction pattern (inset) of $\mathbf{7 b}$ during cooling at $88^{\circ} \mathrm{C}$

In the wide-angle region of $\mathbf{6 d}$ and $7 \mathbf{b}$ a broad halo at $d=4.5 \AA$ and $d=4.3 \AA$ was visible related to the liquid-like alkoxy chains (Fig. $4 \mathrm{a}$ and $\mathrm{b}$ ). In addition, the wide-angle X-ray scattering profile of $\mathbf{7 b}$ showed a multitude of discernable reflections labelled (10), (11), (20), (21), (30), (22) and (40) besides the halo at $d=4.6 \AA$ and a peak at $d=4.3 \AA$, which originate from $\pi-\pi$ interactions between the aromatic cores and correspond to their mean distance within the columns. The latter reflection suggested the formation of an ordered columnar hexagonal mesophase.

For compounds $6 \mathbf{a}$ and $\mathbf{7 d}$ the WAXS samples were prepared by fibre extrusion. Due to the better alignment of the sample in the WAXS of $\mathbf{7 d}$ as compared to $\mathbf{6 a}$ the former was analysed first. The WAXS pattern of 7d showed two sets of diffraction peaks, one in the equatorial and one in the meridional region (Fig. $5 \mathrm{a}$ on the left side). The reflexes in the equatorial region, perpendicular to the fibre axis, correspond to the lattice geometry of the mesophase which was determined as columnar hexagonal (Fig. 3c). The meridional region displayed four pairs of scattering peaks on the left and right hand side of the meridian and two distinct reflexes on the meridian axis, typical for helical superstructures. The obtained WAXS pattern is in good agreement with the simulated one shown in Fig. 5a on the right. ${ }^{45}$ For this simulation it was assumed that, because of their $C_{3}$ symmetry, the molecules stack in a manner where they are rotated by $\varphi=60^{\circ}$. Thus the inner benzene rings are piled up on top of each other while the outer phenyl groups describe a triple helix around the inner column. Owing to the $C_{3}$-symmetry of the triphenylbenzenes only the reflexes on the layer lines $L=3$ and $L=6$ are visible. The reflex on the meridional axis on the layer line $L=6$ corresponds to the stacking inside of the column giving a stacking distance of $d=4.3 \AA$. The layer line $L=3$ corresponds to the pitch $p$ of the helix, which is three molecules 
a)
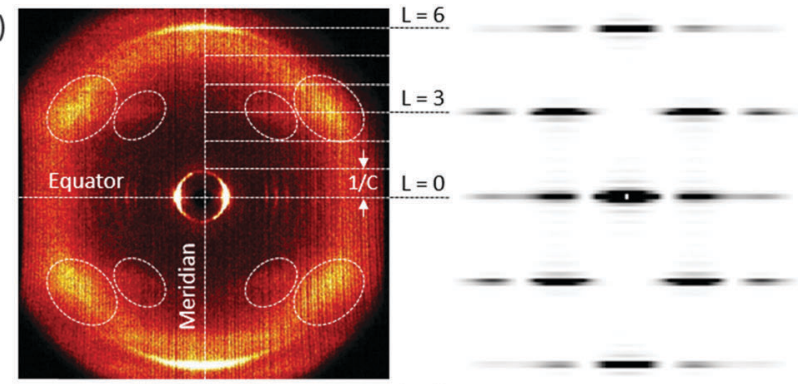

b)

c)
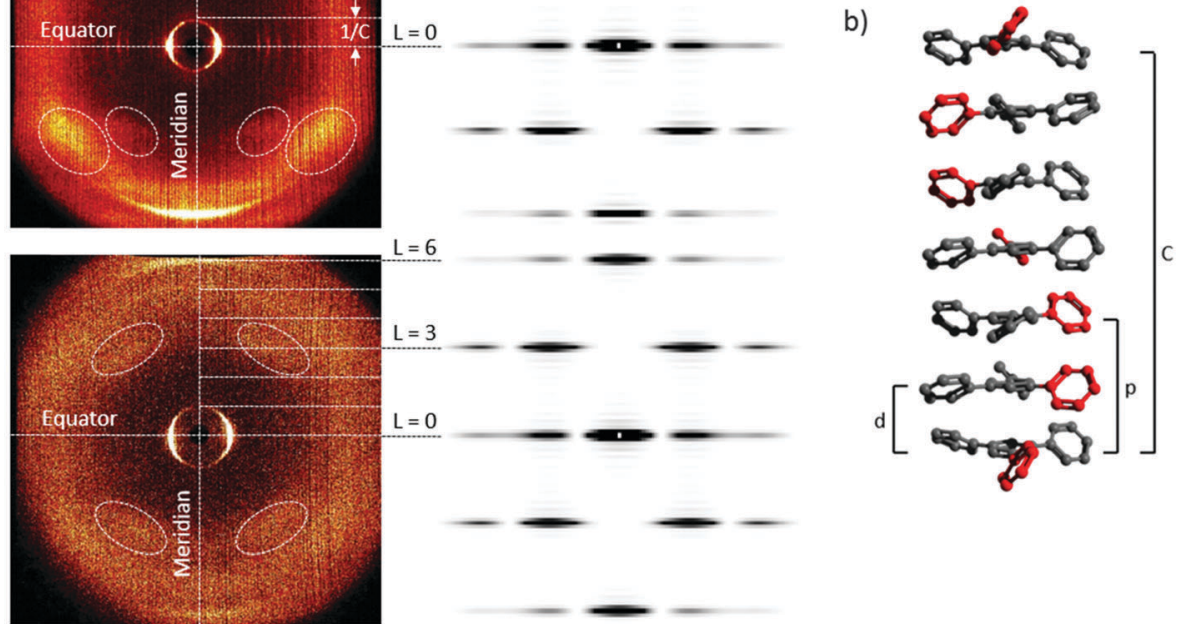

Fig. 5 (a) WAXS pattern of $7 \mathbf{d}$ during heating at $90{ }^{\circ} \mathrm{C}$ (left) and a simulated WAXS pattern (right, HELIX program, $\varphi=60^{\circ}, d=4.3 \AA$ ), (b) schematic structure of a 6 helix with a highlighted (red) rotation of one phenyl group throughout the repeat $\mathrm{C}$, and (c) WAXS pattern of 6 a during heating at $105{ }^{\circ} \mathrm{C}$ (left) and a simulated WAXS pattern (right, HELIX program, $\varphi=60^{\circ}, d=4.0 \AA$ ).

or $p=8.6 \AA$ Altogether the WAXS pattern of $\mathbf{7 d}$ indicates that a triple $6_{1}$ helix with an azimuthal rotation angle of $\varphi=60^{\circ}$, a pitch $p=8.6 \AA$ and a repeat $C$ of three pitches, giving $C=25.8 \AA$, is formed (Fig. 5b). Although this resembles an antiparallel "zig-zag" like packing, the high orientation in the WAXS pattern indicated a periodical setup where the peripheral phenyl rings are twisted in the same direction respective to each other. In an antiparallel stacking a random orientation would be expected.

The WAXS diffractogram of 6a (Fig. $5 c$ on the left side) displayed a similar structure to that of $\mathbf{7 d}$, although the scattering peaks on the equatorial axis were not visible. In the meridional region four peaks on the right and left hand side of the axis were visible as well as two distinct reflexes on the meridional axis. With the assumption of the same rotational angle as for $7 \mathbf{d}\left(\varphi=60^{\circ}\right)$ a diffraction pattern was simulated which is in good agreement with the measurement. ${ }^{45}$ The stacking distance inside the column at $L=6$ is $d=4.0 \AA$ which leads to slightly different helical coefficients from those for $\mathbf{7 d}$.

The analysis of the WAXS pattern indicates the formation of a triple $6_{1}$ helix with a rotational angle of $\varphi=60^{\circ}$, a pitch of $p=8.0 \AA$ and a repeat of $C=24.0 \AA$. In both cases, indication of the handedness could not be obtained. The helix formation seems to be a statistical process due to the absence of chiral information in the triphenylbenzenes, in contrast to the recent work of Casado et al. ${ }^{46}$ who studied $\mathrm{C}_{3}$ tricarboxamides bearing chiral side chains by ECD, VPC and ECL techniques.

\section{Proposed packing model}

The peripheral phenyl rings of 1,3,5-triphenylbenzene derivatives are well known to be twisted by up to $48^{\circ}$ in the solid state. ${ }^{4-49}$
According to Scherowsky this non-planar structure suppresses mesomorphism in hexaoctyloxy- and various ester-functionalized triphenylbenzenes $55^{38}$ As discussed above, side chain elongation in the prepared novel sixfold substituted triphenylbenzenes $\mathbf{5 b - f}$ did not promote liquid crystalline behaviour. However, introducing a third alkoxy group in each peripheral phenyl ring led to the formation of enantiotropic mesophases in derivatives 6a-d and 7a-d. For this purpose, even the minimalistic $\mathrm{OCH}_{3}$ group is sufficient, as was demonstrated for $\mathbf{6 a - d}$. To explain this finding we considered two aspects, the influence of the non-planar triphenylbenzene core system and the varying substitution patterns.

The X-ray data of $\mathbf{6 a}$ and $\mathbf{7 d}$ indicate a helical structure of the formed columns. In a helical setup parts of the voids resulted from the rigid star shape (Fig. 6a) can be compensated by the twisted outer phenyl rings above and beneath each disk in the column, respectively (Fig. 6b). The remaining empty spaces then have to be filled by the peripheral alkoxy chains. This can be achieved either by backfolding of the side chains or by their interdigitation..$^{11,50}$ Both effects should lead to a reduced diameter of the discs (determined by the lattice spacings $a$ of the $\mathrm{Col}_{\mathrm{h}}$ phase geometry) as can be seen in Table 2. For example, the estimated diameters for $\mathbf{6 d}$ and $\mathbf{7 d}$ are the same yet the measured matrix parameter of $\mathbf{6 d}$ is considerably smaller than that of $\mathbf{7 d}$, indicating that the compensation of the minimalistic methoxy groups requires more backfolding or interdigitation of the remaining alkoxy chains. Taking into account that the rigid core cannot take part in these effects, the resulting reduction amounts $47 \%$ for $\mathbf{6 d}$ and $37 \%$ for $\mathbf{7 d}$, respectively.

The absence of mesomorphism in the series of hexasubstituted triphenylbenzenes $\mathbf{5 b}-\mathbf{f}$ is not uncommon among 
a)

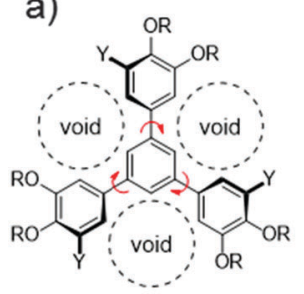

c)

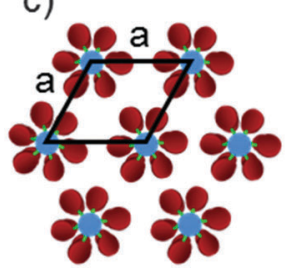

Fig. 6 (a) Rotational latitude of triphenylbenzenes (red arrows) and the voids resulting from the rigid framework, (b) proposed helical stacking model of triphenylbenzenes, and (c) hexagonal lattice consisting of helical columns (lattice spacing a).

Table 2 Calculated ( $a_{\text {calcd, }}$ for the maximum stretched out state) and observed matrix parameter $\left(a_{\text {obsd }}\right)$ from $X$-ray diffraction measurements and reduction of the alkyl chains due to backfolding and interdigitation $\left(\Delta d_{\text {alk }}\right)$

\begin{tabular}{lllll}
\hline Compd & $a_{\text {calcd }} / \AA$ & $a_{\text {obsd }} / \AA$ & $\Delta a / \AA$ & $\Delta d_{\text {alk }}(\%)$ \\
\hline 6a & 36.4 & 25.3 & 11.1 & 44 \\
6d & 43.4 & 28.4 & 15 & 47 \\
7b & 37.8 & 28.3 & 9.5 & 38 \\
7d & 43.4 & 31.8 & 11.6 & 37
\end{tabular}

shape persistent hekates. For structurally related hexa- and nona-alkoxy substituted triphenylboroxines ${ }^{39}$ as well as for hexa- ${ }^{30}$ and nona-alkoxy ${ }^{31}$ substituted triphenyltriazine similar behaviour has been found. This indicates that the formation of a liquid crystalline phase in these small star shaped mesogens strongly depends on the number of alkoxy substituents and not so much on their length. Apparently nine side chains are necessary for successful nanosegregation. This might originate from two effects: the additional group at each peripheral aryl unit increases the shielding of the aromatic core, thus improving segregation of the cores and stabilising columnar mesophases. Alternatively, the additional methoxy group deplanarises the remaining alkoxy chains, forcing them to fill the void between the rings. ${ }^{51}$ Considering this, both possibilities lead to the fact that any substituent in the 5-position of the outer phenyl groups should promote mesomorphism. To elucidate this interesting topic further investigations are currently in progress.

\section{Conclusions}

In conclusion, we have synthesised triphenylbenzenes with 3,4-bisalkoxy- and 3,4,5-trisalkoxyphenyl moieties, which were not liquid crystalline (5), if only two alkoxy substituents were present at each peripheral phenyl ring. However, derivatives 7 with three alkoxy substituents on each phenyl ring showed enantiotropic hexagonal columnar mesophases with phase widths of 75-114 K depending on the chain lengths. Surprisingly, even methoxy served as a third minimalistic alkoxy unit at the peripheral phenyl rings, resulting in enantiotropic hexagonal columnar mesophases with phase widths of $58-80 \mathrm{~K}$ for compounds 6. Extensive XRD studies indicate that a packing model with helical self-assembly seems very likely. The mesomorphic properties indicate that compounds 6 and 7 are indeed the missing links in the series of shape-persistent hekates and might be useful for applications such as lightemitting diodes or photovoltaic cells.

\section{Acknowledgements}

Generous financial support by the Deutsche Forschungsgemeinschaft, the Fonds der Chemischen Industrie (PhD fellowship for S. J. Beardsworth), the Ministerium für Wissenschaft und Kunst des Landes Baden-Württemberg and the Bundesministerium für Bildung und Forschung (shared instrumentation grant 01 RI05177) is gratefully acknowledged.

\section{References}

1 Review: S. Laschat, A. Baro, N. Steinke, F. Giesselmann, C. Hägele, G. Scalia, R. Judele, E. Kapatsina, S. Sauer, A. Schreivogel and M. Tosoni, Angew. Chem., Int. Ed., 2007, 46, 4832.

2 Review: S. Sergeyev, W. Pisula and Y. H. Geerts, Chem. Soc. Rev., 2007, 36, 1902.

3 Review: M. Lehmann, in Handbook of Liquid Crystals, ed. J. W. Goodby, P. J. Collings, T. Kato, C. Tschierske, H. F. Gleeson and P. Raynes, Wiley-VCH, Weinheim, 2nd edn, 2014, vol. 5, p. 243.

4 O. Simalou, P. Xue and R. Lu, Tetrahedron Lett., 2010, 51, 3685.

5 C. Bao, M. Jin, R. Lu, Z. Song, X. Yang, D. Song, T. Xu, G. Liu and Y. Zhao, Tetrahedron, 2007, 63, 7443.

6 M. Tominaga, H. Masu, K. Katagiri and I. Azumaya, Tetrahedron Lett., 2007, 48, 4369.

7 C. Bao, R. Lu, M. Jin, P. Xue, C. Tan, T. Xu, G. Liu and Y. Zhao, Chem. - Eur. J., 2006, 12, 3287.

8 J. Bae, J.-K. Kim, N.-K. Oh and M. Lee, Macromolecules, 2005, 38, 4226.

9 J.-K. Kim, M.-K. Hong, J.-H. Aku and M. Lee, Angew. Chem., Int. Ed., 2005, 44, 328.

10 C.-J. Jong, J.-H. Ryu, J.-D. Lee, D. Sohn and M. Lee, Chem. Mater., 2004, 16, 4226.

11 S. K. Pathak, R. K. Gupta, S. Nath, D. S. S. Rao, S. K. Prasad and A. S. Achalkumar, J. Mater. Chem. C, 2015, 3, 2940.

12 M. Lehmann and M. Huegel, Angew. Chem., Int. Ed., 2015, 54, 4110.

13 M. Lehmann, C. Koehn, H. Meier, S. Renker and A. Oehlhof, J. Mater. Chem., 2006, 16, 441.

14 M. Lehmann, I. Fischbach, H. W. Spiess and H. Meier, J. Am. Chem. Soc., 2004, 126, 772. 
15 S. Xu, Q. Zeng, J. Lu, C. Wang, L. Wan and C.-L. Bai, Surf. Sci., 2003, 538, L451.

16 H. Meier, M. Lehmann, C. Schnorpfeil, M. Fetten and H. Meier, J. Inf. Rec., 2000, 25, 259.

17 H. Meier, M. Lehmann and U. Kolb, Chem. - Eur. J., 2000, 6, 2462.

18 M. Lehmann, B. Schartel, M. Hennecke and H. Meier, Tetrahedron, 1999, 55, 13377.

19 H. Meier and M. Lehmann, Angew. Chem., Int. Ed., 1998, 37, 643.

20 G. Zerban and H. Meier, Z. Naturforsch., 1993, 48b, 171.

21 H. Meier, E. Karpuk and H. C. Holst, Eur. J. Org. Chem., 2006, 2609.

22 H. C. Holst, T. Pakula and H. Meier, Tetrahedron, 2004, 60, 6765 .

23 H. Meier, H. C. Holst and A. Oehlhof, Eur. J. Org. Chem., 2003, 4173.

24 S. Kotha, D. Kashinath and S. Kumar, Tetrahedron Lett., 2008, 49, 5419.

25 H. K. Dambal and C. V. Yelamaggad, Tetrahedron Lett., 2012, $53,186$.

26 Y. Kudo, M. Sakuragi, S. Hashida, R. Kuwakara, T. Ishi, H. Masunaga and K. Sakurai, Polym. J., 2010, 42, 812.

27 T. Ishi, R. Kuwahara, A. Takata, Y. Jeong, K. Sakurai and S. Mataka, Chem. - Eur. J., 2006, 12, 763.

28 A. C.-A. Chen, J. U. Wallace, S. K.-H. Wie, L. Zeng, S. H. Chen and T. N. Blanton, Chem. Mater., 2006, 18, 204.

29 A. C.-A. Chen, J. U. Wallace, L. Zeng, S. K.-H. Wie and S. H. Chen, Proc. SPIE, 2005, 5936.

30 D. Goldmann, A. Nordsieck, D. Janietz, T. Frese, C. Schmidt and J. H. Wendorff, Mol. Cryst. Liq. Cryst., 2004, 411, 1379.

31 H. Lee, D. Kim, H.-K. Lee, W. Qiu, N.-K. Oh, W.-C. Zin and K. Kim, Tetrahedron Lett., 2004, 45, 1019.

32 C.-H. Lee and T. Yamamoto, Mol. Cryst. Liq. Cryst. Sci. Technol., Sect. A, 2002, 378, 13.

33 C.-H. Lee and T. Yamamoto, Bull. Chem. Soc. Jpn., 2002, 75, 615. 34 C.-H. Lee and T. Yamamoto, Tetrahedron Lett., 2001, 42, 3993.
35 O. Simalou, P. Xue and R. Lu, Tetrahedron Lett., 2010, 51, 3685.

36 B. P. Dash, R. Satapathy, J. A. Maguire and N. S. Hosmane, Org. Lett., 2008, 10, 2247.

37 A. N. Cammidge and A. S. H. King, Tetrahedron Lett., 2006, 47, 5569.

38 E. Frackowiak and G. Scherowsky, Z. Naturforsch., 1997, 52b, 1539.

39 T. Wöhrle, A. Baro and S. Laschat, Materials, 2014, 7, 4045.

40 M. Kaller, S. Tussetschläger, P. Fischer, C. Deck, A. Baro, F. Giesselmann and S. Laschat, Chem. - Eur. J., 2009, 15, 9530-9542.

41 B. Schmidt and M. Riemer, J. Org. Chem., 2014, 79, 4104-4118.

42 I. Dierking, Textures of Liquid Crystals, Wiley-VCH, Weinheim, 2003.

43 S. K. Prasad, D. S. S. Rao, S. Chandrasekhar and S. Kumar, Mol. Cryst. Liq. Cryst., 2003, 396, 121-139.

44 M. Lehmann, M. Jahr and J. Gutmann, J. Mater. Chem., 2008, 18, 2995.

45 C. Knupp and J. M. Squire, J. Appl. Crystallogr., 2004, 37, 832.

46 B. Nieto-Ortega, F. García, G. Longhi, E. Castiglioni, J. Calbo, S. Abbate, J. T. López Navarrete, F. J. Ramírez, E. Orti, L. Sánchez and J. Casado, Chem. Commun., 2015, 51, 9781.

47 M. S. Farag, Acta Crystallogr., 1954, 7, 117-121.

48 L. M. C. Beltran, C. Cui, D. H. Leung, J. Xu and F. J. Hollander, Acta Crystallogr., Sect. E: Struct. Rep. Online, 2002, 58, o782-0783.

49 V. Vergadou, G. Pistolis, A. Michaelides, G. Varvounis, M. Siskos, N. Boukos and S. Skoulika, Cryst. Growth Des., 2006, 6, 2486-2492.

50 M. Lehmann, Chem. - Eur. J., 2009, 15, 3638.

51 We are very grateful to one of the referees, who proposed this hypothesis in order to explain the difference between hydrogen and an extra methoxy (or alkoxy) group. 